\title{
Photochromic compounds: Chemistry and application in ophthalmic lenses
}

\author{
John C. Crano, T. Flood, D. Knowles, A. Kumar, B. Van Gemert \\ PPG Industries, Inc. Monroeville, PA USA
}

\begin{abstract}
The preparation of a commercially acceptable plastic photochromic ophthalmic lens requires the incorporation of a number of properties - a neutral activated color, reasonable activation and fade rates, good lifetime, etc.. In this paper we will concentrate on approaches to finding photochromic systems with relatively neutral colors and acceptable rates of activation and fade.

The indolino spironaphthoxazines and related compounds have been known for over 25 years. While offering good photochromic properties with regard to kinetics and photostability, they suffer from the fact that the visible absorption bands of the activated, or open, forms have narrow band widths. Also, without difficult to achieve substitution patterns, the absorption bands appear within a relatively narrow range of wavelengths. Partial neutralization of the activated color of the naphthoxazines was achieved through the use of indolino spirobenzoxazines. The open forms within this family exhibited broad absorption bands but the photochromic activity of each of the members was moderate to low. Enhancement of the photochromic activity was possible with triplet sensitization but at the expense of reduced lifetime. True color neutralization was achieved by coupling pyridobenzoxazines with members of a completely different family of photochromic compounds, the naphthopyrans.
\end{abstract}

\section{INTRODUCTION}

The penetration of plastic lenses into the ophthalmic market is increasing on a worldwide basis. This growth is exemplified by what has happened in the United States. In 1971, the percentage plastic lenses was approximately $5 \%$. By 1994 , this had increased to greater than $85 \%$. Plastic lenses now make up over $50 \%$ of the world market.

In 1966, Corning introduced its Photogray ${ }^{R}$ lenses containing a silver/copper halide photochromic system in mineral glass. The popularity of the glass photochromic lenses plus the increasing market for plastic lenses has resulted in a demand for photochromic systems that are compatible with the matrices used in plastic lenses.

The first commercial plastic photochromic lens was the Photolite ${ }^{\mathrm{TM}}$ lens, introduced by American Optical in 1982. The matrix for the lens was the polymer from allyl diglycol carbonate (ADC), the most common matrix for plastic ophthalmic lenses. The Photolite lens contained an indolino spironaphthoxazine as its photochromic component. The mechanism for the photochromic activity of the spironaphthoxazines, given in scheme $\mathrm{I}$, is well known.

Scheme I
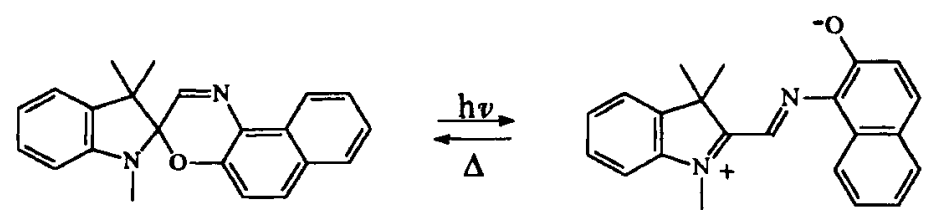

Spironaphthoxazines, a family that has been known for over 25 years ${ }^{1,2}$, are excellent photochromic compounds from the point of view of their photochromic activity and photostability. The open forms of the members of this family have absorption bands within the visible range, normally with maxima from 560 to $630 \mathrm{~nm}$. The absorptions have relatively narrow band widths. The location of the bands can be shifted over a wide range with proper substitution patterns ${ }^{3}$. However, the substitution patterns required to achieve a significant hypsochromic shif $(\max <550 \mathrm{~nm})$ are difficult to accomplish synthetically. The related pyridobenzoxazines $^{4,5}$ have similar absorption patterns but, in general, greater photochromic activity. 


\section{DISCUSSION}

In the development of a photochromic system for commercially acceptable lenses, the color of the activated lens should be as neutral as possible. In order to neutralize the color of the spironaphthoxazines or pyridobenzoxazines, the addition of photochromic compounds with absorption maxima in the range of 400 to $500 \mathrm{~nm}$ is required. The indolino spirobenzoxazines ${ }^{5,6}$ at least partially fill this need. With methoxy groups on the 5- and 7- positions (e.g. 1), compounds with modest activity were obtained. The open forms of these compounds normally have two broad absorption bands in the visible which can be shifted over a moderate range. Figures 1 and 2 display the absorption patterns of the open forms of a typical pyridobenzoxazine and dimethoxybenzoxazine. If these are mixed, a photochromic system with an activated absorption pattern given in Figure 3 is achieved. As the broadness of the absorption pattern illustrates, this system results in an activated color which is more neutral than that with either component used alone. However, the pattern shown in Figure 3 indicates that color neutrality was not obtained.
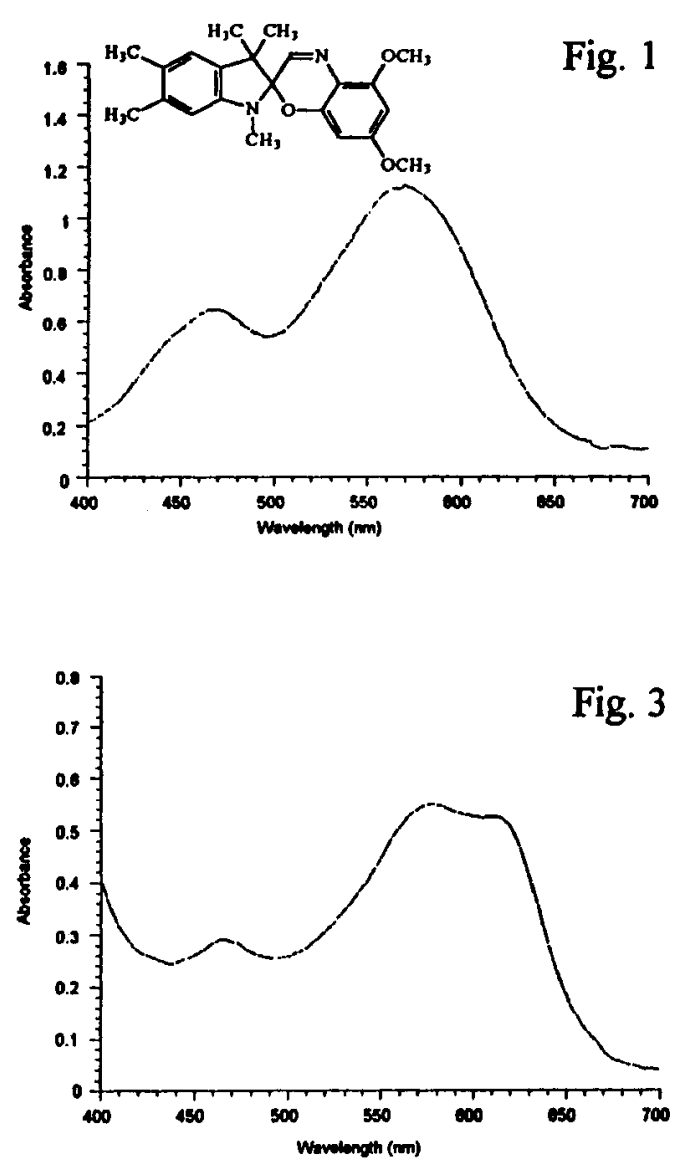

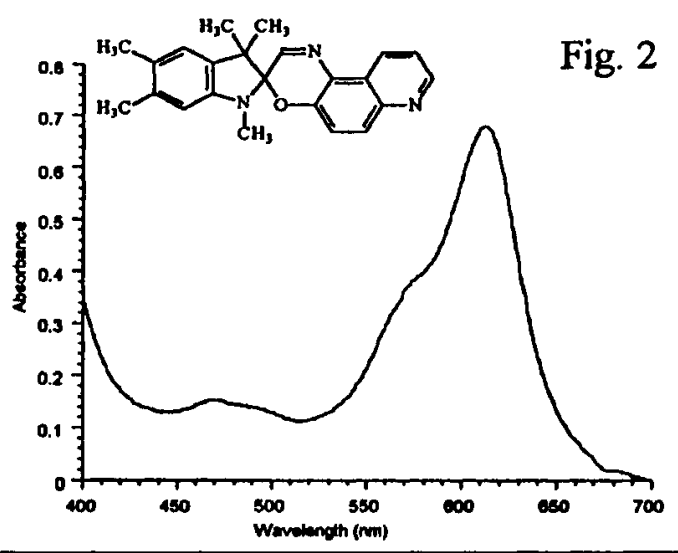

Table 1 Sensitization with 4-Acetylbiphenyl (Poly(vinyl butyral), benzoxazine conc $=1.1 \times 10^{-3} \mathrm{~m}, 24^{\circ} \mathrm{C}$ )

\begin{tabular}{cr}
$\frac{\text { Molar Ratio }}{\text { (Sensitizer:Benzoxazine) }}$ & \multicolumn{2}{l}{ Photochromic } \\
\cline { 2 - 2 } (no sens. $=1.00)$ \\
0.63 & 1.30 \\
1.26 & 1.80 \\
1.89 & 3.34
\end{tabular}

Table 2 Photochromic Properties of Diaryl Naphthopyrans (Matrix $=\mathrm{ADC}, 24^{\circ} \mathrm{C}$ )

\begin{tabular}{ccccc} 
Naphthopyran & $\begin{array}{c}\text { Open Form } \\
\text { (I max })\end{array}$ & $\frac{\text { Response }}{(\Delta \text { OD })}$ & Fade T1/2 \\
II & $432 \mathrm{~nm}$ & 0.36 & $45 \mathrm{sec}$. \\
III & $476 \mathrm{~nm}$ & 1.37 & $>1800 \mathrm{sec}$. \\
\hline
\end{tabular}

The modest photochromic activity of the indolino spirobenzoxazines is due to the location of the UV absorption bands of the spiro forms. With the 5, 7-dimethoxy derivatives, the absorption maxima are all very near $300 \mathrm{~nm}$ which disallows efficient capture of solar radiation. In an attempt to enhance the photochromic activity, the effect of the presence of triplet sensitizers was studied. For the experiments, the spirobenzoxazine, I, was mixed with either 4-acetylbiphenyl or 1-naphthaldehyde in poly(vinyl butyral). As can be seen from the data in Table 1, the addition of 4-acetylbiphenyl resulted in a large enhancement of the photochromic response. The addition of 1-naphthaldehyde led to an even larger enhancement. Unfortunately, the response enhancement was invariably accompanied by a large decrease in the photostability of the photochromic compound. For example, with a molar ratio of 4-acetylbiphenyl to benzoxazine of 1.26 , the almost two fold increase in photochromic response was accompanied by an increase in the rate of photodegradation of at least a factor of five. This is evidence that the normal photochromic behaviour involves largely singlet states. Triplets can also be involved in photochromic activity but when they predominate, an increase in the rate of photodegradation is observed. 


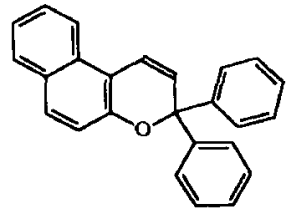

II

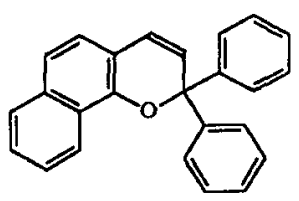

III<smiles>C1=CC(c2ccccc2)(c2ccccc2)Oc2ccc3ccccc3c21</smiles><smiles>O=C1C=Cc2ccccc2/C1=C/C=C(c1ccccc1)c1ccccc1</smiles>

Scheme II

The diaryl naphthopyrans represent another family of photochromic compounds which exhibit excellent photochromic responses. The general family can be separated into two sub-families with rather different photochromic properties, the 3,3-diaryl-3H-naphtho[2,1-b]pyrans (II) and the 2,2-diaryl-2Hnaphtho[1,2-b]pyrans (III). The mechanism for the photochromism of these compounds is similar to that for the oxazines involving opening of the pyran ring (Scheme II). In Scheme II, the open form is drawn as a quinoidal structure rather than with zwitterionic character. The $\mathrm{nmr}$ spectrum of the open form of the unsubstituted [2,1-b]pyran could be obtained in deuteroacetone at $-50^{\circ} \mathrm{C}$. Although not examined here in detail, the spectrum (Figure 4) was best interpreted as resulting from the quinoidal structure.

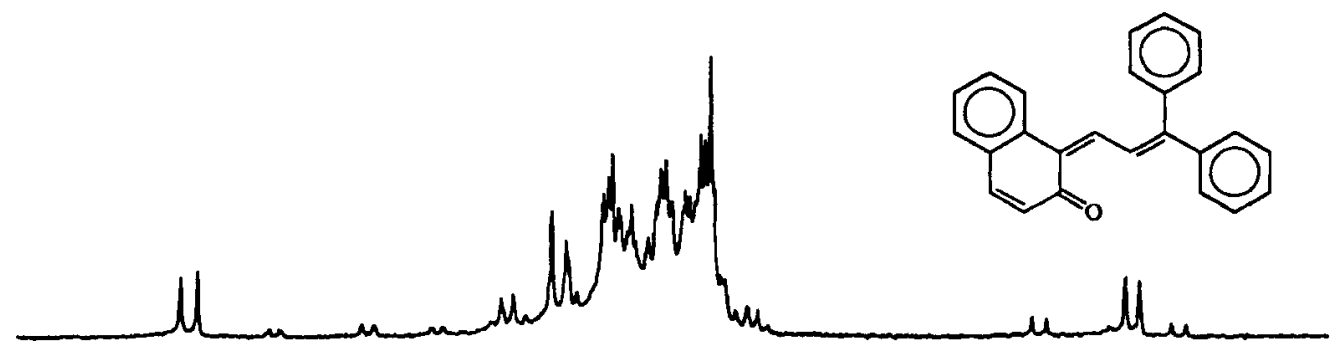

Fig. 4

The photochromic properties of the unsubstituted derivatives of II and III are presented in Table 2. The most important differences between the two compounds are the bathochromic shift that occurs in going from II to III, and the drastically reduced fade rate of III when compared to II. An increase in the rate of fade for III by substitution in the 5 and 6 positions (e.g. 5, 6-dimethyl) was recently published'.

The effect of adding a substituent in the ortho position of one of the phenyl groups in the 3,3diaryl-3H-naphtho[2,1-b]pyrans has been disclosed ${ }^{8}$. The addition of a fluoro, methyl or methoxy group resulted in a reduction in the fade rate and an enhancement of the equilibrium photochromic response. Other effects that have now been investigated are those induced by methoxy substitution in various locations on the [2,1-b]pyran structure. Effects are observed on the UV spectra of the closed forms and the visible spectra of the open forms. As can be seen from the information in Table 3, the most pronounced bathochromic shifts occur with methoxy substitution in the 8-position?.

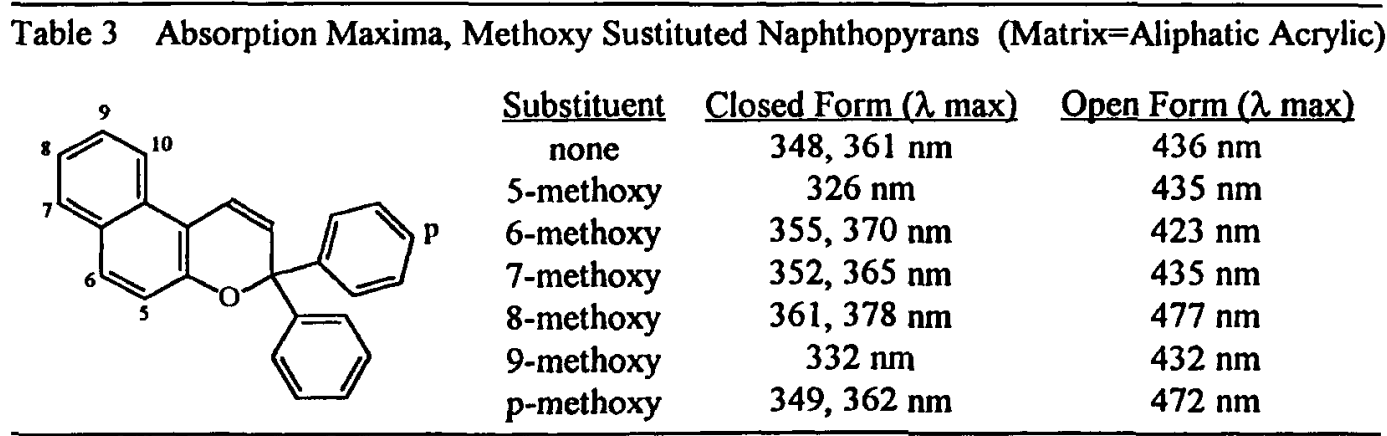

The naphthopyrans can be used with the indolino spironaphthoxazines or pyridobenzoxazines to achieve color neutrality after photochromic activation. This is illustrated in Figures 5, 6, and 7. Although the complementary character of the absorption bands is obvious from Figure 7, the problem of matching the kinetics of the photochromic responses of the two different families remain. 


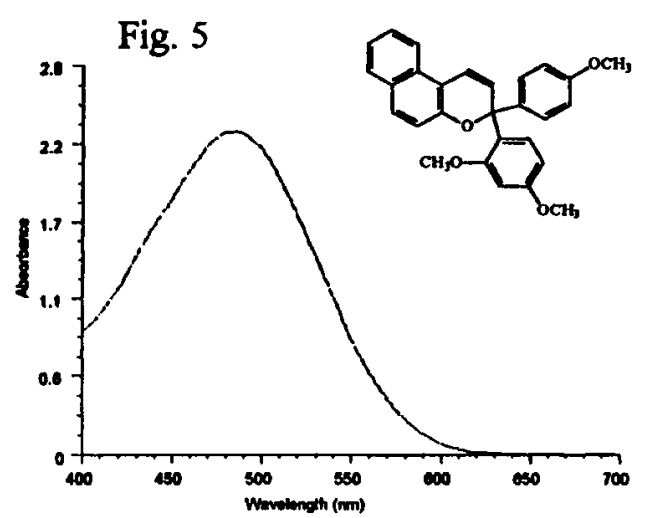

\section{EXPERIMENTAL}

The apparatus used to determine the photochromic properties of samples is described schematically in Figure 8. The equilibrium or study state response was measured as a change in optical density ( $\triangle O D$ ) at the visible absorption maximum. The half-life for the decoloration was measured at $\Delta \mathrm{OD} / 2$.

Fig. 8 Optical Bench
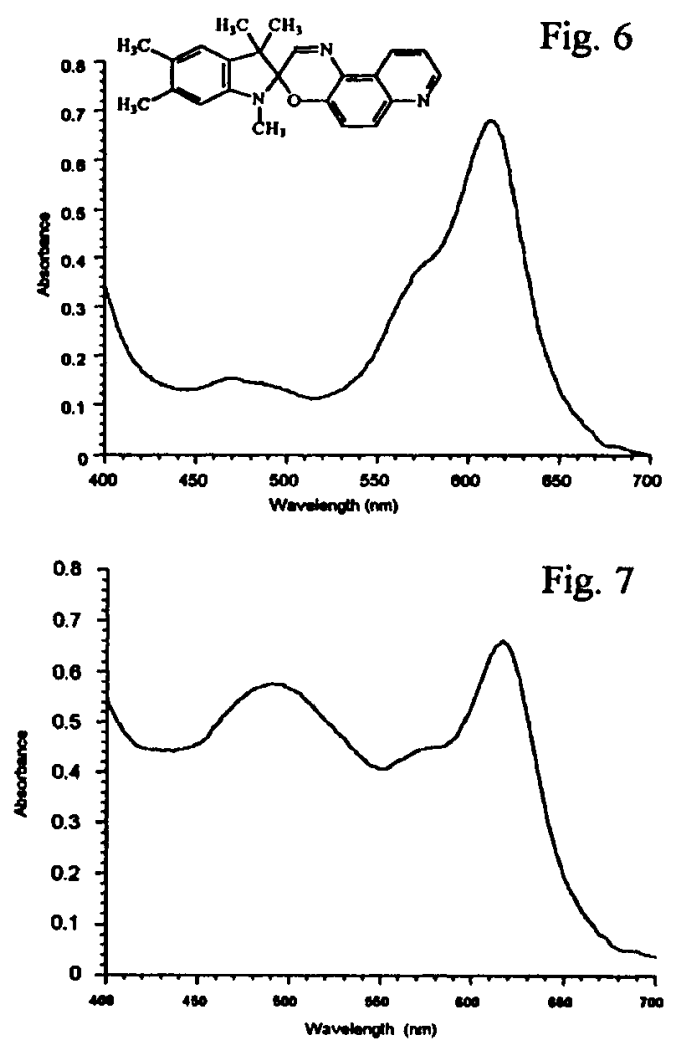

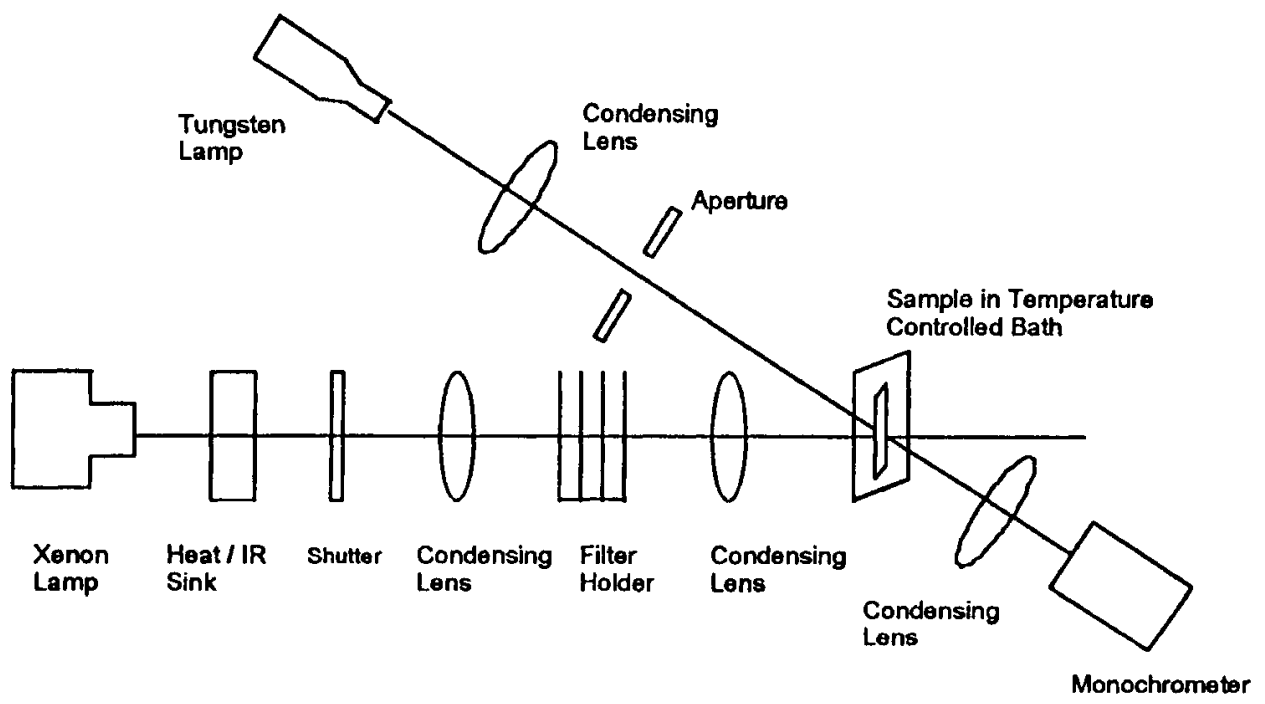

\section{REFERENCES}

1. Ono, H. and Osada, C. (1970) Great Britain 1,186,987 to Fuji.

2. Arnold, G. and Vollmer, H. P. (1970) German Offen. 1,927,849.

3. Rickwood, M., Marsden, S. D., Ormsby, M. E., Staunton, A. L., and Wood, D. W., Mol. Cryst. Liq. Cryst. (1994) Vol. 246, pp. 17-24.

4. Kwak, W. S. and Hurditch, R. (1987) U. S. Patent 4,637,698 (to PPG Industries).

5. Crano, J. C., Welch, C. N., Van Gemert, B., Knowles, D., and Anderson, B., (1993) Photochemistry and Polymeric Systems, ed. Kelly, J. M., McArdle, C. B., and de F. Maunder, M. J., Royal Society of Chemistry, Spec. Pub. 125, 179.

6. Kwak, W. S. and Chen, C. W. (1989) U. S. Patent 4,816,584 (to PPG Industries)

7. Research Disclosure, May, 1994, no. 36144, pp. 267-268.

8. Van Gemert, B., Bergomi, M., and Knowles, D. Mol. Cryst. Liq. Cryst. (1994) Vol. 246, pp. 67-73.

9. Knowles, D. (1993) U. S. Patent 5,238,981 (to Transitions Optical). 